\title{
Bronchoscopic and bronchographic findings in 12 patients with sarcoidosis and severe or progressive airways obstruction
}

\author{
Z F Udwadia, J R Pilling, P F Jenkins, B D W Harrison
}

\begin{abstract}
Twelve patients (8 men), aged 33-67 (mean 49) years, with histologically proved sarcoidosis underwent bronchoscopy. All had symptoms, signs (wheeze in 11 , high pitched inspiratory "squeaks" in six, stridor in three), and physiological abnormalities characteristic of severe or worsening airways obstruction. Eleven patients also underwent bronchography. At the time of bronchoscopy four patients had stage II, one stage III, and seven stage IV sarcoidosis. All patients had a peak expiratory flow (PEF) of $70 \%$ predicted or less and a maximum expiratory flow at $50 \%\left(M_{50}\right)$ and $25 \%\left(M_{25}\right)$ of vital capacity below $35 \%$ predicted. The ratio of their forced expiratory volume in one second to forced vital capacity $\left(F^{2} V_{1}\right)$ FVC) ranged from $37 \%$ to $65 \%$. Fibreoptic bronchoscopy showed single or multiple areas of segmental bronchial stenoses in 10 patients, two of whom had stenotic webs. Bronchography showed that the sites and severity of stenoses were more widespread than suspected from the bronchoscopic findings. Five of the 11 patients undergoing bronchography had bronchiectasis, which was restricted to the upper lobes in three and a lower lobe in one and affected both upper and lower lobes in one patient. The bronchiectasis had not been suspected or diagnosed from the chest radiography or the bronchoscopy.
\end{abstract}

Relatively little attention over the years has focused on endobronchial manifestations of sarcoidosis. Bronchoscopists recognise that the airways are often visibly affected by sarcoidosis and biopsy of even macroscopically normal bronchial mucosa may yield a positive tissue diagnosis. ${ }^{1}$ Physiological evidence of airways obstruction is well recognised in sarcoidosis ${ }^{23}$ and in our practice is the commonest functional abnormality. Although isolated case reports have documented the nature and severity of endobronchial lesions in sarcoidosis, ${ }^{47}$ such patients have not been studied systematically in any detail. We report the bronchoscopic and bronchographic findings in 12 patients with sarcoidosis who developed clinical and physiological evidence of severe or progressive airways obstruction.

\section{Methods}

The 12 patients (eight men) with sarcoidosis were all being followed up for sarcoidosis in our department. Their ages ranged from 33 to 67 years with a mean of 49 years. In addition to clinical examination, chest radiography, and spirometry, all patients had flow-volume measurements performed, lung volumes estimated by helium dilution, and carbon monoxide transfer factor measured by the single breath method. We performed fibreoptic bronchoscopy in all 12 patients. Eleven patients also underwent bronchography, for which a guide wire was passed through the biopsy channel of the bronchoscope, the bronchoscope was removed, and a catheter was advanced into the right main bronchus over the guide wire. A $50 \%$ aqueous suspension of propyliodone (Dionosil Aqueous) (up to $20 \mathrm{ml}$ on each side) was then injected. The indications for proceeding to bronchography were the presence of symptoms, signs, or physiological abnormalities suggesting generalised or localised large airway narrowing.

\section{Results}

At the time of bronchography the findings were as follows.

\section{CLINICAL PROFILE}

There was no clinical evidence of sarcoid lesions in any organs apart from the lungs and mediastinal nodes in five patients. Six had coexisting extrapulmonary manifestations (heart, central nervous system, skin, or eye lesions or hepatosplenomegaly). "Wheeze" was an important symptom in the history of these 11 patients and three patients had considerable stridor. On auscultation of the chest 11 patients had scattered expiratory rhonchi, and six had high pitched inspiratory squawks.

The interval between the diagnosis of sarcoidosis and the onset of clinically obvious airways obstruction is shown in the table. In four patients the presenting symptoms were due to airways obstruction. One patient (No 11 in the table) developed obstructive symptoms 15 years after the diagnosis of sarcoidosis. The mean interval between diagnosis and onset of obstructive features was four years.

\section{CHEST RADIOGRAPHY}

Four patients had stage II and seven had stage IV sarcoidosis (table; for definition of stages see
Department of Respiratory

Medicine,

West Norwich Hospital

Accepted 18 January 1990 
Age, sex, results of lung function testing, ${ }^{\star}$ radiological stage of sarcoidosis at time of presentation and at bronchography, and interval in years between diagnosis and the onset of obstructive features in 12 patients with sarcoidosis

\begin{tabular}{|c|c|c|c|c|c|c|c|c|c|c|c|c|c|}
\hline \multirow{3}{*}{$\begin{array}{l}\text { Patient } \\
\text { No }\end{array}$} & \multirow{3}{*}{$\begin{array}{l}\text { Age } \\
(y)\end{array}$} & \multirow[b]{3}{*}{ Sex } & \multirow{3}{*}{$\begin{array}{l}F E V_{1} \\
\% \text { Pred }\end{array}$} & \multirow{3}{*}{$\begin{array}{l}F E V / F V C \\
(\%)\end{array}$} & \multirow{2}{*}{$P E F$} & \multirow{3}{*}{$\frac{M E F_{50}}{\text { licted) }}$} & \multirow{3}{*}{$M E F_{25}$} & \multirow{3}{*}{$F V C$} & \multirow{3}{*}{$T L C$} & \multirow{3}{*}{ TLCO } & \multicolumn{2}{|c|}{ Radiological staget } & \multirow{3}{*}{$\begin{array}{l}\text { Interval between } \\
\text { diagnosis and onset of } \\
\text { obstructive features (y) }\end{array}$} \\
\hline & & & & & & & & & & & \multirow{2}{*}{$\begin{array}{l}\text { At time of } \\
\text { diagnosis }\end{array}$} & \multirow{2}{*}{$\begin{array}{l}\text { At time of } \\
\text { bronchography }\end{array}$} & \\
\hline & & & & & $1 \% \mathrm{pr}$ & & & & & & & & \\
\hline 1 & 42 & $\mathbf{F}$ & 61 & 65 & 58 & 32 & 28 & 73 & 76 & 63 & II & IV & 2 \\
\hline 2 & 39 & $\mathbf{M}$ & 42 & 44 & 49 & 13 & 8 & 76 & 93 & 65 & I & II & 1 \\
\hline 3 & 40 & $\mathbf{M}$ & 26 & 34 & 51 & 10 & 10 & 62 & 89 & 52 & II & IV & 12 \\
\hline 4 & 41 & $\mathbf{F}$ & 57 & 63 & 61 & 31 & 34 & 68 & 71 & 52 & II & IV & 4 \\
\hline 5 & 33 & $\mathbf{M}$ & 63 & 52 & 70 & 25 & 23 & 101 & 106 & 76 & II & IV & 4 \\
\hline 6 & 52 & $\mathbf{F}$ & 60 & 55 & 49 & 23 & 16 & 83 & 100 & 80 & 0 & II & 0 \\
\hline 7 & 50 & $\mathbf{M}$ & 52 & 47 & 54 & 18 & 12 & 86 & 95 & 99 & II & II & 1 \\
\hline 8 & 50 & $\mathbf{M}$ & 31 & 43 & 60 & 11 & 8 & 73 & 79 & 76 & IV & IV & 8 \\
\hline 9 & 58 & $\mathbf{M}$ & 25 & 40 & 38 & 7 & 10 & 58 & 121 & 65 & I & II & 0 \\
\hline 10 & 60 & $\mathbf{M}$ & 54 & 50 & 34 & 15 & 10 & 83 & 81 & 68 & II & - & 0 \\
\hline 11 & 54 & $\mathbf{M}$ & 49 & 37 & 42 & 14 & 8 & 101 & 94 & 72 & II & IV & 15 \\
\hline 12 & 67 & $\mathbf{F}$ & 72 & 46 & 54 & 21 & 25 & 109 & 99 & 70 & III & IV & 0 \\
\hline
\end{tabular}

*Absolute values for each patient available from the authors on request.

tStage 0-normal chest radiograph; stage I-bilateral hilar lymphadenopathy; stage II-bilateral hilar lymphadenopathy with diffuse parenchymal changes; stage III-diffuse parenchymal changes without hilar lymphadenopathy; stage IV-evidence of pulmonary fibrosis.

$\mathrm{FEV}_{1}$-forced expiratory volume in one second; FVC - forced vital capacity; PEF-peak expiratory flow; $\mathrm{MEF}_{50}, \mathrm{MEF}_{25}-\mathrm{maximum}$ expiratory flows at $50 \%$ and $25^{\circ}$ of vital capacity; TLC-total lung capacity; TLCO-carbon monoxide transfer factor.

footnote to table). None had any atelectasis or signs to suggest bronchiectasis on the plain chest radiograph.

\section{LUNG FUNCTION}

All patients had moderate or severe airways obstruction, with concave expiratory flowvolume curves, either in isolation (nine patients) or in combination with a restrictive defect (three patients) - see table. All had a peak expiratory flow of $70 \%$ predicted or less. There was no appreciable reversibility after $5 \mathrm{mg}$ nebulised terbutaline in any of the patients.

\section{FIBREOPTIC BRONCHOSCOPY}

The bronchoscopic appearances were normal in two patients. Ten had characteristic endobronchial plaques and single or multiple areas of narrowing and stenosis of segmental bronchi. In two patients the degree of stenosis was extreme, so that only a pinhole opening was visible in the right lower lobe bronchus (patient 2 ) or the right uppper lobe bronchus (patient 11). Two of the patients showed a web like narrowing of multiple segmental orifices (fig 1).

Figure 1 Web like narrowing of the left upper lobe as shown by bronchoscopy. This has resulted in near total occlusion with only a pinhead sized orifice.

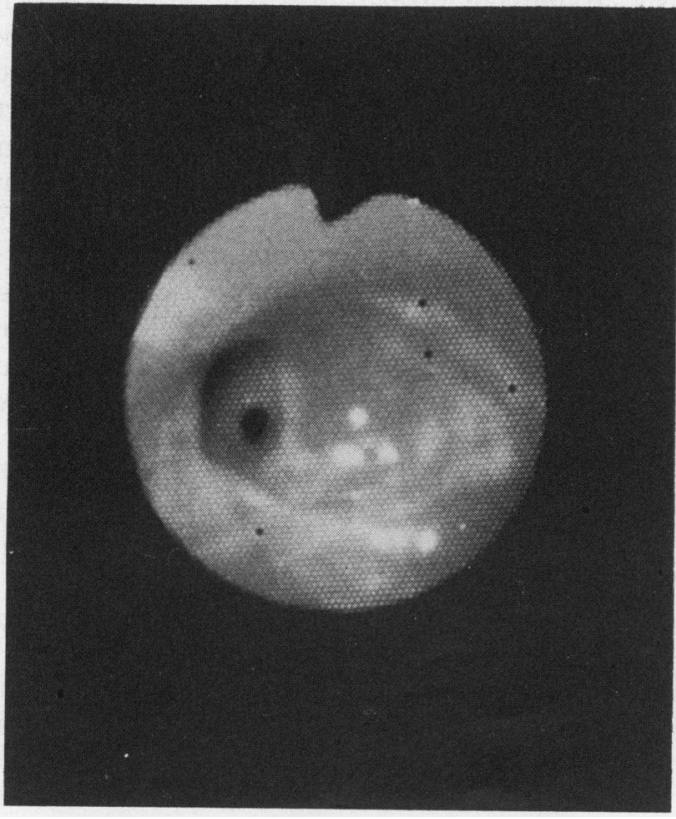

BRONCHOGRAPHY

Bronchograms in 11 patients showed that the site and degree of stenosis were even more extensive than suspected from the bronchoscopic findings. The bronchi were distorted and crowded in seven patients, irregular in outline in nine, and stenosed and narrowed in all 11 (fig 2). The stenoses were widespread, affecting all lobes in one patient, four lobes in four patients, three lobes in three patients, and two lobes in one patient. In the remaining two patients there was solitary segmental narrowing of a single segmental branch (upper lobe in one, lower lobe in the other). The stenoses were of moderate degree (less than 50\% luminal narrowing) in seven and severe $(50 \%$ or more luminal narrowing) in four patients.

Five patients also had bronchiectasis. In four there was mild bronchial dilatation and loss of the normal distal tapering, but one man had gross saccular bronchiectasis (fig 3). The bronchiectasis was in the upper lobes in three, in a lower lobe in one, and in both upper and lower lobes in one patient.

\section{Discussion}

In 1957, Citron and Scadding ${ }^{4}$ were the first to report the bronchographic findings in patients with sarcoidosis who had presented with dyspnoea, cough, and wheeze. Bronchography showed widespread stenoses in all three and poststenotic dilatation in one. In the same year Honey and Jepson ${ }^{5}$ reported two patients with sarcoidosis who had presented with stridor, in both of whom bronchography showed widespread stenoses, with dilatation of smaller bronchi in one patient. Hadfield et al described four patients with sarcoidosis with widespread bronchial stenoses, though none had bronchiectasis. ${ }^{6}$ Dunnill ${ }^{8}$ also described bronchiectasis pathologically in sarcoidosis. Bronchostenosis, visible at bronchoscopy, has been reported in up to $21 \%$ of patients with stage I sarcoidosis, in $27 \%$ of those with stage II, and in $26 \%$ of those with stage III disease - but without any mention of the severity of the stenosis or the duration of symptoms before bronchoscopy. 
Figure 2 Two bronchograms: (a) From patient 11, showing complete occlusion of the anterior and apicoposterior segmental bronchi of the left upper lobe and a long narrowed segment in the lingular bronchus. There is some irregularity of the airways and in the lower lobe the apical segmental bronchus is completely occluded. (b) From patient 6 , showing a stenotic narrowing of the middle lobe orifice and narrowing of the main stem lower lobe bronchus before it divides.

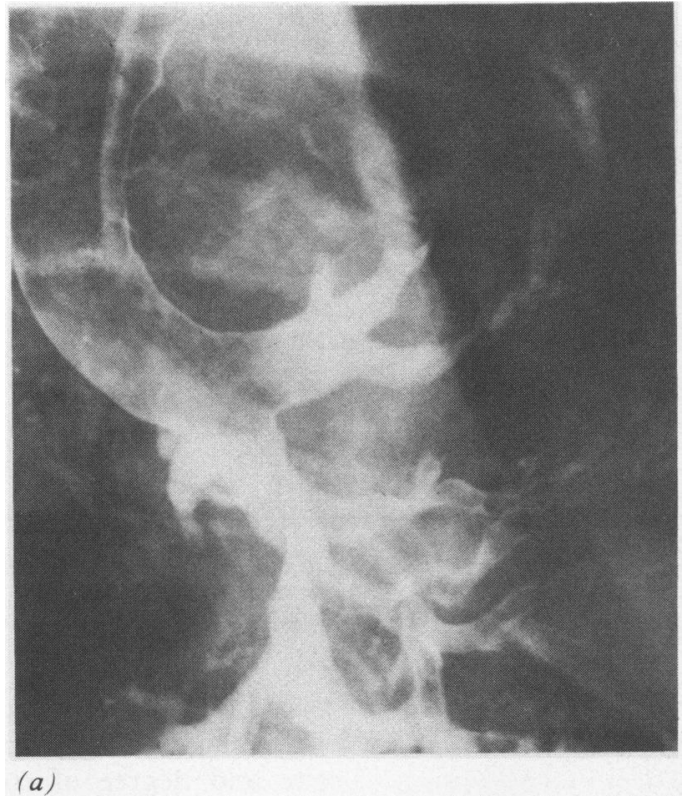

We report the bronchographic findings in 11 patients with sarcoidosis. All had presented with symptoms of airways narrowing or developed increasing dyspnoea associated with worsening airway obstruction while under observation. All had clinically obvious expiratory wheezing, six had inspiratory "squawks," and three had stridor. Lung function tests confirmed airways obstruction in all of them, with no reversibility after nebulised terbutaline. Bronchography showed widespread bronchial stenoses in all and bronchiectasis in five. The bronchographic appearance of widespread bronchostenoses in combination with bronchiectasis has not received attention in previous case reports. We know of no other condition in which widespread bronchostenoses and bronchiectasis occur together except tuberculosis, and we would like to highlight this combination as an important consequence of bronchial lesions in sarcoidosis. Our patient 2 also appeared in the study reported from Cambridge $^{6}$ (also as patient 2). His earlier bronchogram, in 1978, showed bronchial stenoses but no bronchiectasis. Extensive bron-

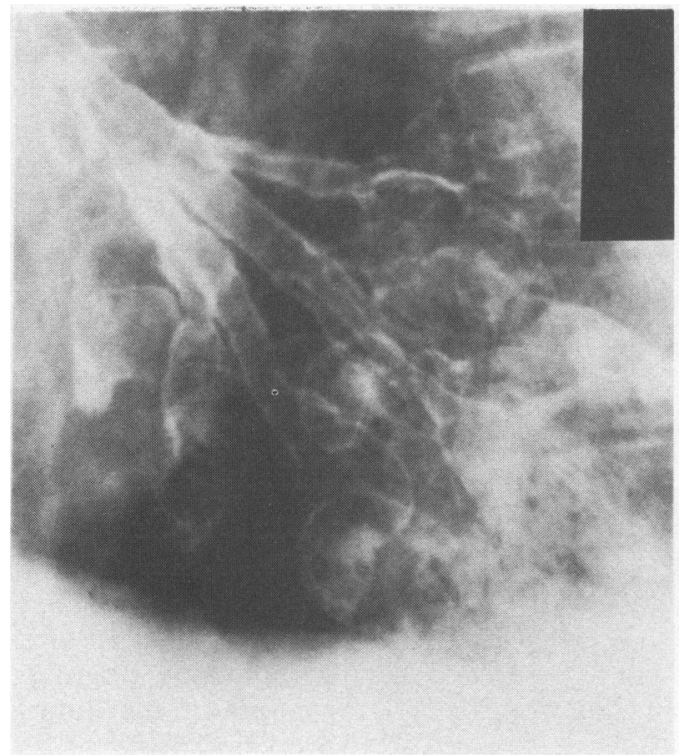

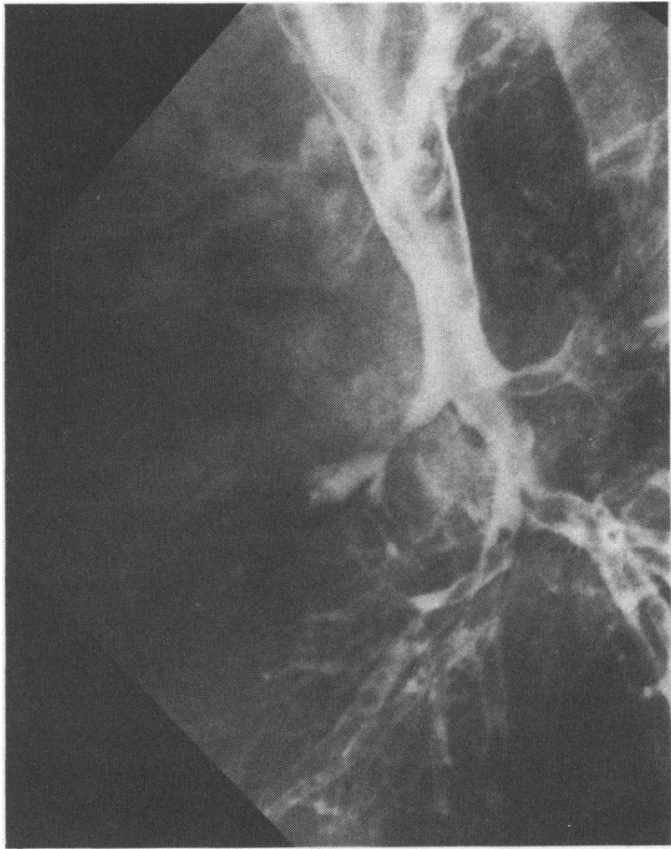

(b)

chiectasis had developed by the time of the second bronchogram in 1984.

Endobronchial manifestations of sarcoidosis are very common but have received surprisingly little attention. An obstructive defect is the most common (personal observation) and blind biopsy of apparently normal bronchial mucosa may yield granulomas in up to $37 \%$ of patients. ${ }^{9}$ Endobronchial sarcoidosis does not, however, usually progress to bronchial narrowing and stenosis sufficient to cause symptoms and disability. When stenosis does occur its pathogenesis remains unclear but there are several possible explanations. Granulomatous inflammation may affect the mucosa of the bronchial wall directly ${ }^{10-12}$ and this is probably the cause of the irregularities in the bronchial wall seen in nine of our patients. The extensive lung fibrosis that may occur in the later stages of sarcoidosis may constrict and distort the major bronchi ${ }^{14}$ and there was evidence of this in seven patients. Much more rarely, enlarged hilar nodes or perihilar fibrosis may compress major bronchi. The pathogenesis of the bronchiectasis is also uncertain. It may be due to destruction or weakening of the bronchial wall by sarcoid granulomatous inflammation or result from atelectasis and infection beyond bronchi compressed by large hilar nodes. ${ }^{14} 15$

Fibreoptic bronchoscopy reveals narrowing of segmental orifices in some patients with sarcoidosis, the proportion ranging from $2 \%{ }^{16}$ and $8^{\circ} \%{ }^{17}$ to $26 \%$ in a recent study. ${ }^{9}$ Bronchoscopy is not, however, an accurate method for determining either the extent or the severity of bronchial stenoses, as the bronchographic appearances in our patients show. Furthermore, bronchoscopy is unable to detect localised bronchiectasis, which five of our patients had in addition to their bronchial stenoses.

There are important practical reasons for performing bronchography in this group of patients with sarcoidosis. Corticosteroid treatment, oral or inhaled, may be tried and may 
bring some relief if obstruction is caused by granulomas. Mechanical dilatation of proximal stenoses may be attempted at bronchoscopy. ${ }^{18}$ When bronchiectasis is discovered or confirmed, postural drainage may result in symptomatic improvement and reduction in the amount of sputum produced.

We are grateful to Mrs A L Neale for typing the manuscript.

1 Mitchell DM, Mitchell DN, Emerson CJ. Transbronchial lung biopsy through fibreoptic brochoscope in diagnosis of sarcoidosis. $B r$ Med J 1980;280:679-81.

2 Levinson RS, Metzger LF, Stanley NN, et al. Airway Levinson RS, Metzger LF, Stanley NN, et al.
function in sarcoidosis. Am J Med 1977;62:51-9.

3 Bower JS, Dantzker DR. Airway obstruction in sarcoidosis. Am Rev Respir Dis 1977;115(4):91-5.

4 Citron KM, Scadding JG. Stenosing non-caseating tuberculoses (sarcoidosis) of the bronchi. Thorax 1957;12:10-7.

5 Honey M, Jepson E. Multiple bronchostenosis due to sarcoidosis. Report of two cases. Br Med J 1957;ii:1330-4.
6 Hadfield JW, Page RL, Flower CDR, Stark JE. Localised airway narrowing in sarcoidosis. Thorax 1982;37:443-7. 7 Manning PJ, Murphy E, Callaghan B. Bronchostenosis due to sarcoidosis. Ir Med J 1984;77:210-2.

8 Dunnill MS. Pulmonary pathology. Edinburgh: Churchill Livingstone, 1982:377.

9 Armstrong JR, Radke JR, Kvale PA, Eichenhorn MS, Popovich J. Endoscopic findings in sarcoidosis. Characteristics and correlations with radiographic staging and teristics and correlations with radiographic staging and
bronchial mucosal biopsy yield. Ann Otol 1981;90:339-43. 10 Siltzbach LE, Som ML. Sarcoidosis with bronchial involvement. Mt Sinai J Med 1953;19:473-80.

11 Stahle I. Bronchial involvement in pulmonary sarcoidosis. Acta Med Scand (suppl) 1964;425:234-6.

12 Benedict EB, Castleman B. Sarcoidosis with bronchial involvement. N Engl J Med 1941;224:186-9.

13 Coates EO, Comroe JH Jr. Pulmonary function studies in sarcoidosis. J Clin Invest 1951;30:848-51.

14 Dibinedetto RJ, Ribaudo C. Bronchopulmonary sarcoidosis. Am Rev Respir Dis 1966;94:952-8.

15 Longcope WT, Freiman DG. A study of sarcoidosis. Longcope WT, Freiman DG. A study
Medicine (Baltimore) 1952;31:1-132.

16 Weisner B. Diagnostic bronchologique de la sarcoidose. Bronches 1973;23:104-11.

17 Olsson T, Bjormstad-Pettersen H, Stjerberg NL. Bronchostenosis due to sarcoidosis. Chest 1979;75:663-6.

18 Iles PB. Multiple bronchial stenosis: treatment by mechanical dilation. Thorax 1981;36:784-6. 